\title{
PENGARUH PEMBERIAN POLI ALUMINIUM CHLORIDA TERHADAP KADAR PHOSPAT DAN TOTAL DISSOLVED SOLID PADA AIR LIMBAH RUMAH SAKIT ORTOPEDI PROF. DR. R. SOEHARSO SURAKARTA
}

\author{
SumardiningsihS.T \\ Program Studi Teknik Lingkungan, Fakultas Teknik,Universitas Kristen Surakarta \\ Elvis Umbu Lolo,M.T \\ Program Studi Teknik Lingkungan, Fakultas Teknik,Universitas Kristen Surakarta \\ eumbulolo@yahoo.co.id \\ Widianto,S.T.,M.T \\ Program Studi Teknik Lingkungan, Fakultas Teknik,Universitas Kristen Surakarta \\ widyasel@gmail.com
}

\begin{abstract}
Abstrak
Limbah cair rumah sakit merupakan salah satu sumber pencemaran air yang sangat potensial. Oleh karena itu maka setiap rumah sakit diharuskan mengolah limbah cair sampai memenuhi persyaratan standar yang berlaku, diantaranya untuk kandungan phospat yang dapat menimbulkan kerugian seperti pertumbuhan ganggang yang cepat dan tidak terkendali, sehingga air menjadi keruh dan berbau yang menyebabkan habisnya kadar oksigen dalam sungai. Salah satu metode untuk menurunkan kandungan phospat yaitu dengan penambahan Poli Aluminium Chlorida (PAC). Tujuan dari penelitian ini adalah untuk mengetahui pengaruh pemberian Poli Aluminium Chlorida (PAC) dengan dosis 0,01 gr/l; 0,02 gr/l; 0,03 gr/l; 0.04 gr/l; dan 0,05 gr/l terhadap kadar phospat dan Total Dissolved Suspended (TDS) pada air limbah Rumah Sakit Ortopedi Prof. DR. R. Soeharso Surakarta serta untuk mengetahui dosis efektif PAC.Metode penelitian dengan melakukan eksperimental di laboratorium. Adapun sampel air limbah diambil dari Rumah Sakit Ortopedi Prof. DR. R. Soeharso Surakarta, sedangkan percobaan dilakukan di Perusahaan Daerah Air Minum (PDAM) Surakarta dan pemeriksaan sampel dilakukan di Laboratorium Pusat Matematikan dan Ilmu Pengetahuan Alam (MIPA) Universitas Sebelas Maret Surakarta.Hasil penelitian menunjukkan bahwa pemberian PAC dapat menurunkan kadar phospat dalam air limbah dengan penurunan rata-rata kadar phospat dengan dosis $0,01 \mathrm{gr} / 1$ sebesar $35,24 \%$, dosis $0,02 \mathrm{gr} / \mathrm{l}$ sebesar $44,28 \%$, dosis $0,03 \mathrm{gr} / \mathrm{l}$ sebesar $49,70 \%$, dosis $0,04 \mathrm{gr} / 1$ sebesar $68,67 \%$ dan $0,05 \mathrm{gr} / 1$ sebesar $44,88 \%$ serta menaikkan kadar TDS dengan kenaikan rata-rata kadar TDS dengan dosis 0,01 gr/l sebesar $1,3 \%$, dosis $0,02 \mathrm{gr} / 1$ sebesar $1,9 \%$, dosis $0,03 \mathrm{gr} / \mathrm{l}$ sebesar $2 \%$, dosis 0,04 gr/l sebesar 3,9 \% dan dosis 0,05 gr/l sebesar 4,6 \%. Pengaruh pemberian Poli Aluminium Chlorida (PAC) terhadap kadar phospat yaitu pada penambahan Poli Aluminium Chlorida (PAC) dari 0,01 gr/l sampai dengan 0,04 gr/l kadar phospat mengalami penurunan secara optimum yaitu dengan kadar $0,014 \mathrm{mg} / \mathrm{l}$, sedangkan pada penambahan Poli Aluminium Chlorida (PAC) dari 0,04 gr/l sampai dengan 0,05 gr/l mengalami kenaikan. Pengaruh PAC terhadap kadar TDS yaitu bahwa semakin tinggi dosis PAC maka kadar TDS semakin tinggi.
\end{abstract}

Kata kunci: Air limbah, Phospat, Poli Aluminium Chlorida 


\section{Abstract}

Hospital sewage is one source of water contamination potential. Therefore, each hospital is required to treat wastewater to meet the requirements of applicable standards, including for the content of phosphate which could result in losses as a rapid algae growth and uncontrolled, so the water becomes murky and smells that cause oxygen levels dlam endless river. One method to reduce the phosphate content by the addition of Poly Aluminium chloride (PAC). The purpose of this study was to determine the effect of Poly Aluminium chloride (PAC) with a dose of $0.01 \mathrm{~g} / \mathrm{l}$; $0.02 \mathrm{~g} / \mathrm{l} ; 0.03 \mathrm{~g} / \mathrm{l} ; 0.04 \mathrm{~g} / 1$ and $0.05 \mathrm{~g} / 1$ of phosphate levels and Suspended Total Dissolved (TDS) in water waste Prof. Orthopedic Hospital. DR. R. Soeharso Surakarta as well as to determine the effective dose of PAC. This research method is to conduct experimental laboratory as well as descriptive data analysis conducted to determine the effective dose of PAC. The results showed that administration of PAC can reduce levels of phosphate in wastewater with an average reduction of phosphate levels with a dose of $0.01 \mathrm{~g} / 1$ at $35.24 \%$, the dose of $0.02 \mathrm{~g} / 1$ at $44.28 \%$, doses of 0 , $03 \mathrm{~g} / 1$ at $49.70 \%$, the dose of $0.04 \mathrm{~g} / 1$ at $68.67 \%$ and $0.05 \mathrm{~g} / 1$ by $44.88 \%$ and raise the TDS level with the average increase in TDS levels at a dose of $0.01 \mathrm{~g} / 1$ of $1.3 \%$, the dose of $0.02 \mathrm{~g} / 1$ of $1.9 \% \mathrm{n}$, the dose of $0.03 \mathrm{~g} / 1$ of $2 \%$, the dose of $0.04 \mathrm{~g} / 1$ of $3.9 \%$ and the dose of $0,05 \mathrm{~g} / 1$ of $4.6 \%$. The conclusion of this study is that the effect of Poly Aluminium Chloride (PAC) on levels of phosphate which is the higher dose of PAC, the levels of phosphate on the downside, while the influence of PAC on levels of TDS is that the higher dose of PAC, the higher the TDS levels. From this research can be suggested to the hospital to be able to apply these research results related to levels of phosphate in waste water.

Keywords: Phosphate, PolyAluminiumChloride, Wastewater

\section{PENDAHULUAN}

Rumah sakit adalah merupakan fasilitas sosial yang melakukan pelayanan kesehatan dengan inti kegiatan pelayanan preventif, kuratif, rehabilitatif dan promotif, yang tidak dapat dipisahkan dengan masyarakat. Keberadaannya sangat diharapkan oleh masyarakat karena sebagai manusia atau masyarakat tentu menginginkan agar kesehatan tetap terjaga. Di masa lalu, suatu rumah sakit dibangun di suatu wilayah yang jaraknya cukup jauh dari daerah pemukiman dan biasanya dekat dengan sungai dengan pertimbangan agar pengelolaan limbah baik padat maupun cair tidak berdampak negatif terhadap penduduk, atau bila ada dampak negatif maka dampak tersebut dapat diperkecil.

Pengolahan limbah cair tersebut dilakukan agar tidak mencemari lingkungan diantaranya terhadap kandungan phospat. Sumber limbah cair dengan kandungan phospat tinggi di rumah sakit adalah tempat pencucian alat laboratorium, laundry, kamar mandi dan dapur. Terhadap kandungan phospat yang tinggi tersebut perlu diadakan penanganan lebih lanjut. Karena kadar phospat yang tinggi dapat mengganggu keseimbangan biologis sebab ganggang akan tumbuh terlalu cepat, sehingga dapat menghabiskan kadar oksigen terlarut dalam air yang akan mengganggu kelestarian ekosistem perairan.

\section{TINJAUAN PUSTAKA Pengertian limbah cair rumah sakit}

Jaringan jalan adalah satu kesatuan jaringan jalan yang terdiri atas sistem jaringan primer dan sistem jaringan jalan sekunder yang terjalin dalam hubungan hierarkis. Sedangkan sistem jaringan jalan adalah satu kesatuan ruas jalan yang saling menghubungkan dan mengikat pusat-pusat pertumbuhan 
dengan wilayah yang berada dalam pengaruh pelayanannya dalam satu hubungan hierarkis atau pengelompokan jalan (https://id.wikipedia.org/wiki/jaringan_ jal-an).

\section{Karakteristik limbah cair rumah sakit}

Secara umum limbah cair rumah sakit terdiri dari dua kelompok, yaitu:

a. Limbah cair klinis

Limbah cair klinis adalah limbah yang berasal dari pelayanan medis, perawatan gigi, farmasi, pengobatan, perawatan, penelitian atau pendidikan yang menggunakan bahan-bahan beracun, infeksius berbahaya.

b. Limbah cair domestic

Limbah cair domestik ini umumnya berasal dari buangan kamar mandi, dapur, dan air bekas pencucian pakaian.

\section{Limbah Cair Rumah Sakit Ortopedi Prof. DR. R. Soeharso}

Unit-unit penghasil limbah cair di Rumah Sakit Ortopedi Prof. Dr. R. Soeharso adalah semua unit pelayanan medis yang ada maupun unit pelayanan non medis, diantaranya adalah:

1. Dari pelayanan medis:

2. Dari pelayanan non medis:

\section{Dampak Buruk Limbah Cair}

Menurut Ricki M. Mulia (2005), air limbah yang tidak dikelola dengan baik dapat menimbulkan dampak buruk bagi makhluk hidup dan lingkungannya, yaitu:

- Gangguan kesehatan

- Penurunan kualitas lingkungan

- Gangguan terhadap keindahan

Kandungan Phospat dalam Limbah Cair

Menurut G. Alaerts dan Sri Sumestri Santika (1984), phospat terdapat dalam air limbah sebagai senyawa ortophospat, poliphospat, dan phospat organik. Ortophospat adalah senyawa monomer seperti $\mathrm{H}_{2} \mathrm{PO}_{4}{ }^{-}$, $\mathrm{HPO}_{4}{ }^{2-}$, dan $\mathrm{HPO}_{4}{ }^{3-}$, sedangkan poliphospat merupakan senyawa polimer seperti $\left(\mathrm{PO}_{3}\right)_{6}{ }^{3-}, \mathrm{P}_{3} \mathrm{O}_{10}{ }^{5-}$, dan $\mathrm{P}_{2} \mathrm{O}_{7}{ }^{4-}$ yang banyak digunakan dalam pembuatan detergen sintetis. Phospat organik adalah phospat yang terikat dengan senyawa-senyawa organik sehingga tidak berada dalam larutan secara terlepas. Komponen phospat dipergunakan untuk membuat sabun sebagai pembentuk buih. Dan adanya phospat dalam air limbah dapat menghambat penguraian pada proses biologis.

\section{Zat Padat Terlarut (TDS)}

TDS (Total Dissolved Solid) adalah jumlah total zat padat yang terlarut dalam air. Zat padat tersebut adalah kandungan mineral seperti besi, klorida dan lain-lain (http://www.airminumisiulang.com). TDS biasanya terdiri dari zat organik, garam anorganik dan gas terlarut. Bila TDS bertambah maka kesadahan akan naik pula, selanjutnya efek TDS ataupun kesadahan terhadap kesehatan tergantung pada zat kimia penyebab masalah tersebut (Juli Soemirat Slamet, 1996). Jumlah zat padat terlarut ini dapat digunakan sebagai indikator terjadinya pencemaran air. Sumber utama untuk TDS dalam peairan adalah limpahan dari pertanian,limbah rumah tangga dan industri.

\section{Koagulasi dan Flokulasi}

Koagulasi merupakan proses penambahan dan pencampuran suatu koagulan dan dilanjutkan dengan destabilisasi koloid serta diakhiri oleh pembentukan partikel berukuran besar (flok). Pada proses koagulasi terjadi pembentukan inti endapan yang ditandai dengan pengadukan cepat.

Sedangkan flokulasi adalah suatu proses penggumpalan partikel-partikel terstabilisasi. 


\section{Poli Aluminium Chlorida (PAC) sebagai koagulan}

PAC merupakan garam yang dibentuk oleh aluminium-aluminium chlorida khusus ditentukan untuk memberi daya koagulasi dan flokulasi yang lebih besar dibanding garamgaram aluminium dan besi lainnya. PAC adalah polimer komplek berantai panjang yang mempunyai rumus umum $\mathrm{Al}_{\mathrm{m}}(\mathrm{OH})_{\mathrm{n}}(\mathrm{Cl})_{3 \mathrm{~m}-\mathrm{n}}$, dimana flok yang terbentuk lebih padat dan kecepatan mengendap yang tinggi.

\section{METODE PENELITIAN Lokasi Penelitian}

1. Rumah Sakit Ortopedi Prof. DR. R. Soeharso Surakarta.

2. Perusahaan Daerah Air Minum (PDAM) Kota Surakarta yang beralamat di Jalan Adi Sucipto Surakarta.

3. UPT Laboratorium Pusat Matematika dan Ilmu Pengetahuan Alam (MIPA) Universitas Sebelas Maret (UNS) Surakarta.

\section{Bahan Penelitian}

Bahan penelitian adalah limbah cair Rumah Sakit Ortopedi Prof. DR. R. Soeharso Surakarta yang diambil dari outlet (setelah pengolahan).

\section{Variabel Penelitian \\ Variabel bebas \\ - Konsentrasi PAC mulai dari $0,01 \mathrm{~g} / \mathrm{l} ; 0,02 \mathrm{~g} / \mathrm{l} ; 0,03 \mathrm{~g} / \mathrm{l} ; 0,04$ $\mathrm{g} / \mathrm{l} ; 0,05 \mathrm{~g} / \mathrm{l}$ \\ Variabel terikat \\ - Parameter Phospat $\left(\mathrm{PO}_{4}\right)$ dengan satuan $\mathrm{mg} / \mathrm{l}$ \\ - Parameter Total Dissolved Solid (TDS) dengan satuan $\mathrm{mg} / \mathrm{l}$}

\section{Teknik Pengambilan Data}

Pengumpulan data dalam penelitian ini meliputi data primer yaitu data hasil analisa parameter phospat dan TDS di laboratorium.

Teknik pengumpulan data dilakukan dengan percobaan di Perusahaan Daerah Air Minum (PDAM) Kota Surakarta yang selanjutnya dilakukan analisis di laboratorium pusat MIPA Universitas Sebelas Maret Surakarta agar dapat mengetahui besarnya kadar parameter phospat dan TDS sebelum dan sesudah pengolahan guna menentukan besarnya efektifitas penggunaan PAC.

Sedangkan data sekunder diambil dari studi pustaka dan hasil penelitian serta sumber lain yang mendukung penelitian ini.

\section{Analisa Data}

Analisa data dilakukan secara deskriptif dengan membandingkan kadar phospat dan TDS dalam limbah cair sebelum dan sesudah diberi perlakuan dengan penambahan Poli Aluminium Chlorida (PAC).

\section{HASIL DAN PEMBAHASAN Hasil Penelitian}

Berdasarkan penelitian didapatkan hasil pemeriksaan air limbah sebelum dan sesudah perlakuan dengan pemberian Poli Aluminium Chlorida (PAC)

a. Kadar Phospat

Pengukuran kadar phospat pada limbah cair dilakukan sebelum dan sesudah perlakuan dengan pemberian Poli Aluminium Chlorida (PAC), yang dilakukan pada tanggal 7 April 2011 sebanyak delapan belas kali.

Adapun data hasil pengukuran sebelum perlakuan dapat dilihat pada lampiran 1 nomor 2 tentang phospat, sedangkan hasil pengukuran phospat setelah perlakuan dapat dilihat pada lampiran 2, 3 dan 4 masing-masing nomor 2 tentang phospat. 


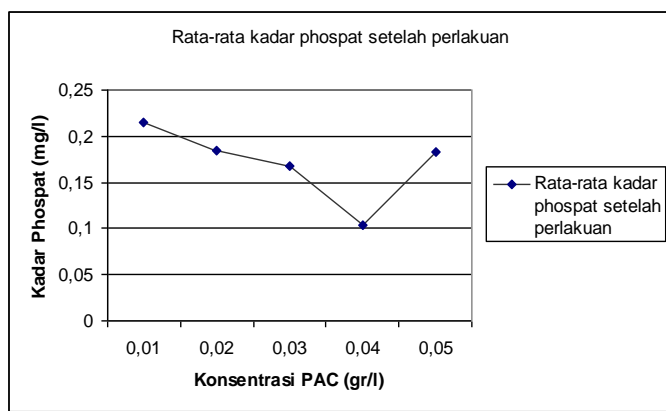

Gambar 1. Grafik pengaruh pemberian Poli AluminiumChlorida (PAC) terhadap kadar Phospat

\section{b. Total Dissolved Solid (TDS)}

Pengukuran kadar TDS pada limbah cair dilakukan sebelum dan sesudah perlakuan dengan pemberian PAC, yang dilakukan pada tanggal 7 April 2011 sebanyak delapan belas kali.

Adapun data hasil pengukuran sebelum perlakuan dapat dilihat pada lampiran 1 nomor 1 tentang Total Dissolved Solid (TDS), sedangkan hasil pengukuran Total Dissolved Solid (TDS) setelah perlakuan dapat dilihat pada lampiran 2, 3 dan 4 masing-masing nomor 1 tentang Total Dissolved Solid (TDS).

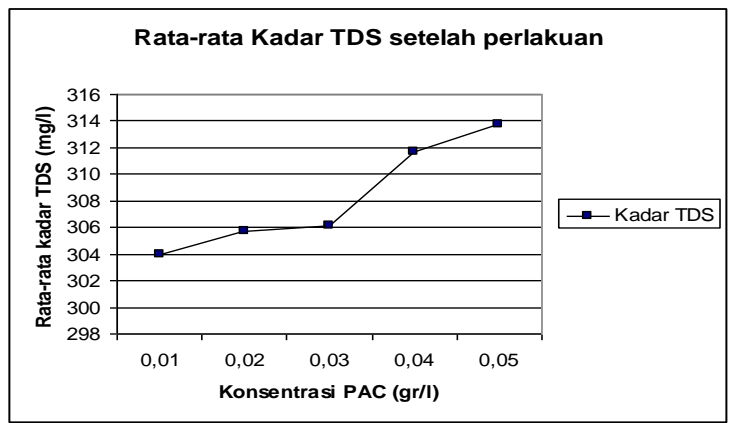

Gambar 2. Grafik pengaruh pemberian Poli Aluminium Chlorida (PAC) terhadap kadar Total Dissolved Solid (TDS)

\section{Pembahasan}

\section{Phospat}

Dalam penelitian, pengukuran kadar phospat dilakukan sebanyak delapan belas kali yaitu sebelum perlakuan dengan penambahan PAC dan sesudah perlakuan dengan penambahan PAC.
Mengingat PAC bekerja dengan jangkauan dosis yang lebih kecil, maka penelitian ini menggunakan PAC dengan dosis $0,01 \mathrm{gr} / 1 ; 0,02 \mathrm{gr} / 1 ; 0,03$ $\mathrm{gr} / 1 ; 0,04 \mathrm{gr} / 1$ dan $0,05 \mathrm{gr} / 1$.

Dari lampiran 1 nomor 2 tentang phospat dapat dilihat bahwa rata-rata kadar phospat sebelum perlakuan dengan penambahan PAC adalah sebesar 0,332 mg/l. Kadar phospat tersebut masih berada di bawah nilai ambang batas yang dipersyaratkan dalam Peraturan Daerah Propinsi Jawa Tengah No. 10 tahun 2004 tentang baku mutu air limbah untuk kegiatan Rumah Sakit yaitu 2 mg/l. Walaupun demikian penelitian ini dilakukan bertujuan untuk mengetahui bagaimana pengaruh PAC terhadap kadar phospat dalam air limbah.

Berdasarkan hasil penelitian setelah dilakukan dengan penambahan PAC, sesuai dengan lampiran 2, 3 dan 4 tentang phospat, maka didapatkan ratarata kadar phospat pada perlakuan pertama dengan penambahan PAC 0,01 gr/l sebesar 0,215 mg/l, pada perlakuan kedua dengan penambahan PAC 0,02 gr/l sebesar $0,185 \mathrm{mg} / \mathrm{l}$, pada perlakuan ketiga dengan penambahan PAC 0,03 gr/l sebesar $0,167 \mathrm{mg} / \mathrm{l}$, pada perlakuan keempat dengan penambahan PAC 0,04 gr/l sebesar 0,104 mg/l, dan pada perlakuan kelima dengan penambahan PAC 0,05 gr/l sebesar 0,183 mg/l.

Dengan demikian dapat diketahui bahwa penambahan PAC ke dalam air limbah dapat menurunkan kadar phospat. Hal ini terjadi karena kandungan phospat akan terpisah dengan sendirinya pada saat pemberian PAC dan selanjutnya membentuk endapan. Penurunan kadar phospat dalam air limbah tersebut tidak berjalan seiring dengan penambahan dosis koagulan (PAC) yang semakin meningkat. Pada penambahan PAC dosis $0,01 \mathrm{gr} / 1: 0,02 \mathrm{gr} / \mathrm{l}: 0,03 \mathrm{gr} / \mathrm{l}$ dan $0,04 \mathrm{gr} / 1$ terjadi kenaikan prosentase penurunan kadar phospat secara 
signifikan, tetapi pada penambahan PAC dosis $0,05 \mathrm{gr} / \mathrm{l}$ terjadi penurunan prosentase kadar phospat dari dosis sebelumnya. Tingkat ketelitian dalam pemeriksaan laboratorium dapat menjadi penyebab terjadinya hal tersebut. Walaupun prosentase penurunan kadar phospat selalu naik tapi waktu yang diperlukan untuk pengendapan sangat bervariasi. Hal itu disebabkan flok-flok yang terbentuk saat flokulasi tidak sama beratnya. Jika flok yang terbentuk sangat ringan maka membutuhkan waktu pengendapan yang lebih lama sedangkan flok yang berat membutuhkan waktu pengendapan yang relatif cepat. Berdasarkan prosentase penurunan kadar phospat dan waktu yang diperlukan untuk pengendapan, maka penurunan efektif kadar phospat terdapat pada penambahan PAC dengan dosis 0,04 gram/liter. Berdasarkan pengamatan deskriptif tersebut maka dosis efektif untuk menurunkan kadar phospat dalam air limbah adalah 0,04 gram/liter. Karena pada dosis 0,04 gram/liter tersebut kadar phospat bisa turun sebesar 68,67 persen dan dalam waktu yang pendek yaitu 6 menit 20 detik.

Dalam pengolahan limbah cair, phospat berfungsi untuk proses metabolisme organisme-organisme biologis. Namun jika kadar phospat terlalu rendah $(<0,01 \mathrm{mg} / \mathrm{l})$ maka pertumbuhan tanaman akan terhalang, begitu juga dengan sebaliknya, bila kadar phospat tinggi maka pertumbuhan tanaman dan ganggang tidak terbatas lagi dan dalam hal itu akan mengganggu proses metabolisme organisme-organisme biologis karena menghalangi masuknya sinar matahari ke dalam air, sehingga proses fotosintesis yang dapat menghasilkan oksigen akan berkurang yang selanjutnya akan menyebabkan kehidupan aquatik termasuk ikan akan terganggu atau mati.
Kenaikan kandungan phospat dapat terjadi karena hasil buangan manusia yang berupa air seni dan komponen phospat yang dipergunakan untuk membuat sabun (detergen) sebagai pembentuk buih yang akan menambah jumlah total dari phospat (Sugiharto, 1987).

\section{Total Dissolved Solid (TDS)}

Selain dilakukan pengukuran kadar phospat juga dilakukan pengukuran kadar Total Dissolved Solid (TDS), yaitu total padatan yang terlarut di dalam limbah cair tetapi dengan tidak melihat zat padat terlarut lainnya, walaupun TDS tidak dipersyaratkan di Peraturan Daerah Propinsi Jawa Tengah Nomor 10 Tahun 2004 tentang Baku Mutu Air Limbah untuk Rumah Sakit. Hal ini dilakukan karena untuk mengetahui pengaruh pemberian PAC terhadap kadar zat padat terlarut dengan tidak melihat zat padat terlarut lainnya. Pengukuran kadar TDS ini juga dilakukan sebanyak delapan belas kali meliputi pengukuran sebelum perlakuan dengan penambahan PAC maupun setelah perlakuan dengan penambahan PAC dengan dosis 0,01 $\mathrm{gr} / 1 ; 0,02 \mathrm{gr} / 1 ; 0,03 \mathrm{gr} / 1 ; 0,04 \mathrm{gr} / 1$ dan $0,05 \mathrm{gr} / \mathrm{l}$.

Dari lampiran 1 nomor 1 tentang Total Dissolved Solid (TDS) dapat dilihat bahwa rata-rata kadar TDS sebelum perlakuan dengan penambahan PAC adalah $300 \mathrm{mg} / \mathrm{l}$. Sedangkan setelah perlakuan dengan penambahan PAC sesuai dengan lampiran 2, lampiran 3 dan lampiran 4 tentang Total Dissolved Solid (TDS) didapatkan rata-rata kadar TDS yaitu pada perlakuan pertama dengan penambahan PAC 0,01 gr/l sebesar 304 $\mathrm{mg} / \mathrm{l}$, pada perlakuan kedua dengan penambahan PAC 0,02 gr/l sebesar 305,7 mg/l, pada perlakuan ketiga dengan penambahan PAC 0,03 gr/l sebesar 306 $\mathrm{mg} / \mathrm{l}$, pada perlakuan keempat dengan penambahan PAC 0,04 gr/l sebesar 311,7 
$\mathrm{mg} / \mathrm{l}$ dan pada perlakuan kelima dengan penambahan PAC 0,05 gr/l sebesar 313,7 $\mathrm{mg} / \mathrm{l}$.

Dari data percobaan tersebut terlihat bahwa semakin banyak konsentrasi PAC yang ditambahkan semakin tinggi prosentase kenaikan kadar TDS nya. Hal ini disebabkan karena penambahan PAC yang berlebihan sehingga partikel koloid tidak terdestabilisasikan tetapi terestabilisasi. Selain itu disebabkan juga karena pengadukan yang terlalu cepat sehingga flok yang sudah terbentuk menjadi pecah sehingga menimbulkan partikel koloid menjadi terlarut kembali. Seiring dengan banyaknya kadar zat padat yang terlarut, kadar phospat juga mengalami penurunan. Tetapi zat padat yang terlarut di sini bukan berarti hanya berasal dari phospat tetapi juga dari kandungan kimia yang lain dalam air limbah tersebut.

Apabila hasil TDS tersebut dihubungkan dengan waktu yang diperlukan untuk pengendapan, maka tidak berjalan seiring dengan penambahan dosis PAC yang semakin meningkat. Ada yang semakin tinggi dosis PAC semakin sedikit waktu pengendapannya tetapi ada juga yang semakin tinggi dosis PAC semakin lama waktu pengendapannya. Hal tersebut dikarenakan adanya perbedaan jenis partikel di dalam air limbah yang berada di masing-masing beaker Jartest. Partikel-partikel yang terlalu ringan akan mengendap dalam waktu yang pendek, sedangkan partikel yang berat akan mengendap dalam waktu yang cepat.

Zat padat terlarut sendiri lebih banyak berasal dari senyawa-senyawa anorganik maupun organik seperti air buangan dari dapur dan pencucian.

\section{KESIMPULAN DANSARAN Kesimpulan}

Sesuai dengan tujuan penelitian ini, maka berdasarkan hasil penelitian dapat ditarik kesimpulan sebagai berikut:
1. Kadar phospat dalam limbah cair dari effluent di Instalasi Pengolahan Air Limbah Rumah Sakit Ortopedi Prof. DR. R. Soeharso Surakarta sebelum dilakukan pemberian Poli Aluminium Chlorida (PAC) rata-rata adalah sebesar 0,332 mg/l. Sedangkan kadar Total Dissolved Solid (TDS) nya ratarata sebesar $300 \mathrm{mg} / \mathrm{l}$.

2. Kadar phospat dalam limbah cair dari effluent di Instalasi Pengolahan Air Limbah Rumah Sakit Ortopedi Prof. DR. R. Soeharso Surakarta setelah dilakukan pemberian Poli Aluminium Chlorida (PAC) pada perlakuan pertama dengan penambahan PAC $0,01 \mathrm{gr} / \mathrm{l}$ rata-rata sebesar $0,215 \mathrm{mg} / \mathrm{l}$, pada perlakuan kedua dengan penambahan PAC $0,02 \mathrm{gr} / \mathrm{l}$ rata-rata sebesar $0,185 \mathrm{mg} / \mathrm{l}$, pada perlakuan ketiga dengan penambahan PAC 0,03 gr/l rata-rata sebesar $0,167 \mathrm{mg} / \mathrm{l}$, pada perlakuan keempat dengan penambahan PAC $0,04 \mathrm{gr} / \mathrm{l}$ rata-rata sebesar $0,104 \mathrm{mg} / \mathrm{l}$, dan pada perlakuan kelima dengan penambahan PAC 0,05 gr/l rata-rata sebesar 0,183 mg/l. Sedangkan kadar Total Dissolved Solid (TDS) setelah dilakukan pemberian Poli Aluminium Chlorida (PAC), pada perlakuan pertama dengan penambahan PAC 0,01 gr/l sebesar $304 \mathrm{mg} / \mathrm{l}$, pada perlakuan kedua dengan penambahan PAC 0,02 gr/l sebesar 305,7 mg/l, pada perlakuan ketiga dengan penambahan PAC 0,03 gr/l sebesar $306 \mathrm{mg} / \mathrm{l}$, pada perlakuan keempat dengan penambahan PAC 0,04 gr/l sebesar 311,7 mg/l dan pada perlakuan kelima dengan penambahan PAC 0,05 gr/l sebesar 313,7 mg/l. Adapun pengaruh PAC terhadap kadar phospat adalah bahwa semakin tinggi dosis PAC maka kadar phospat akan turun sehingga kualitas air limbah menjadi baik tanpa memperhatikan kandungan kimia yang lain. Sedangkan pengaruh PAC terhadap kadar TDS adalah bahwa 
semakin tinggi dosis PAC maka kadar TDS semakin tinggi yang mengakibatkan kualitas air limbah menurun.

3. Dosis efektif untuk menurunkan kadar phospat dalam air limbah adalah 0,04 gram/liter.

\section{Saran}

1. Jika kadar phospat dalam limbah cair di Rumah Sakit Ortopedi Prof. DR. R. Soeharso melebihi ambang batas, maka upaya untuk menurunkan kadar phospat tersebut dapat menggunakan Poli Aluminium Chlorida (PAC) dengan dosis efektif 0.04 gram/liter.

2. Pemberian Poli Aluminium Chlorida (PAC) supaya dilakukan pada lokasi setelah proses decanting pada Instalasi Pengolahan Air Limbah Rumah Sakit Ortopedi Prof. DR. R. Soeharso Surakarta.

3. Bagi peneliti lain, disarankan untuk melakukan penelitian lanjutan dengan menggunakan dosis Poli Aluminium Chlorida (PAC) yang berbeda serta diperhitungkan dengan biaya penggunaan Poli Aluminium Chlorida (PAC), dan menentukan dosis optimum dengan regresi garis linier.

\section{DAFTAR PUSTAKA}

Alaerts, G, Santika dan Sri Sumestri Santika, 1987, Metoda Penelitian Air. Surabaya: Usaha Nasional.

Darmasetiawan, Martin, 2004, Sarana Sanitasi Perkotaan. Ekamitra Engineering.

\section{Dasar-dasar Teknologi Pengolahan Limbah Cair, http://www.airminumisiulang.com, diakses tanggal 5 April 2011}

Jurusan Teknik Lingkungan Universitas Kristen Surakarta, 2002, Petunjuk Penulisan Skripsi

\section{Limbah Rumah Sakit,} http://www.kelair.bppt.go.id, diakses tanggal 3 Maret 2011

Mulia, M. Ricki, 2005, Kesehatan Lingkungan. Jakarta: Graha Ilmu.

Notoatmojo, Soekidjo, 2003, Ilmu Kesehatan Masyarakat (Prinsipprinsip Dasar). Jakarta: Rineka Cipta

Pemakaian Bahan Kimia, http://www.scribd.com, diakses tanggal 26 Pebruari 2011

Pencemaran Air, http://www.bplhdjabar.go.id, diakses tanggal 21 Pebruari 2011

Proses Pengolahan Air, http://repository.usu.ac.id, diakses tanggal 24 Maret 2011

Reynolds, Tom D, 1977, Unit Operations and Processes in Environmental Engineering Monterey California

Siregar, A, Sakti, 2005, Instalasi Pengolahan Air Limbah. Yogyakarta: Kanisius

Slamet, Juli Soemirat, 1996, Kesehatan Lingkungan. Yogyakarta: Gajah Mada University Press.

Sugiharto, 1987, Dasar-dasar Pengelolaan Air Limbah. Jakarta: UI-Press 